\title{
Determining the Causes of the Main Uncontrolled Stops on the TOP DRIVE System during Drilling with the Maintenance Plan Study
}

\author{
Al-Shami Thair \\ $\mathrm{PhD}$ candidate Polytechnic University of Bucharest, \\ Romania
}

\author{
Stan Marius, Avram Lazar \\ The Oil and Gas University of Ploiesti, \\ Romania
}

\begin{abstract}
Petroleum Drilling and Drilling Platforms for on / off-shore drilling operations are structured according to the shareholders used. Their use focuses on finding new ways to strengthen ways to reduce energy consumption and increase reliability and reduce the technical risks that may arise during operation. Optimization of the structure depends on the drilling method in relation to the operating systems that fulfill the necessary functions for the technological process.
\end{abstract}

Keywords-Maintenance; Method, Top Drive, System

\section{I.INTRODUCTION}

Petroleum Drilling Drilling Platforms for on / offshore drilling operations are structured according to the shareholders used.

Their use focuses on finding new ways to strengthen ways to reduce energy consumption and increase reliability and reduce the technical risks that may arise during operation.

Structure optimization depends on the drilling method in relation to the operating systems that perform the functions required for the eco-process.

Handling of the drill string is a complex operation in which many auxiliary operations are required, both for the extraction operation and for the load introducing operation.

The removal of the drill string consists of its decomposition in steps of a certain length and its storage in the stack. Although drilling operations such as insertion operations occupy a significant portion of the total maneuvering time, that is to say the operation of the drilling rig, they are in themselves unproductive operations and the time during which such an operation is carried out is called auxiliary time (TA).

Hence, the major desideratum that led to the emergence of modern drilling and intervention facilities is that the auxiliary time is minimal, if possible even zero, which means that the maneuvering speed has always the maximum value dictated by the technological process served and the strength of the structure's resistance structure.

\section{GENERAL RELATIONSHIP FOR THE TOTAL TIME OF HOISTING(MANEUVER) TUBULAR MATERIAL IN THE WELL}

Starting from the general relation of the total maneuver time $(\mathrm{Tm})$ (eg extraction of the drilling gasket from the depth $\mathrm{H}),(1)$, we can say that:

$$
\mathrm{T}_{\mathrm{m}}=\frac{H}{V_{r}}+\frac{H}{l_{p}}\left(\frac{t_{1}+t_{3}}{2}+t_{4}\right)
$$

$\mathrm{Tm}$ - the total extraction maneuver;

$\mathrm{H}$ - maximum depth;

$\mathrm{Vr}$ - the speed of the hook during the stabilized regime;

t1 - the duration of the transient start-up regime;

t3 - the lengthy period of stay at stop;

t4 - duration of ancillary operations (TA text is in the text);

lp - the length of a step.

For the optimal length of step lp, resulting from a technical-economic calculation, which usually has the lpo $=27$ $\mathrm{m}$ value, the minimum amount of total maneuver time is obtained for the minimum auxiliary time. Similarly, the study of the power consumption (Pm) consumed at maneuver and the hook speed in the stabilized $\mathrm{Vr}$ period, lead to similar conclusions regarding the value that the auxiliary time should have.

In a unitary approach it emerges as an important special conclusion that the total maneuver time Tm is minimal when the auxiliary time is minimal (if possible even zero). This condition, correlated with the influences $\mathrm{lp}, \mathrm{P}, \mathrm{Vr}$, shows that it is possible for a drilling installation to perform efficient, step-less maneuvering operations at relatively small maneuvering powers and handling the load at speeds of low values.

This is the evolution in the sense of modernizing and even radically changing the IFI work systems worldwide with finality in the design and construction of installations with a structure different from the classical image. The development of unconventional drilling methods, in which process management is done using the process computer, using the previously described structure with the maximum critical element (SG), Figure 1. 


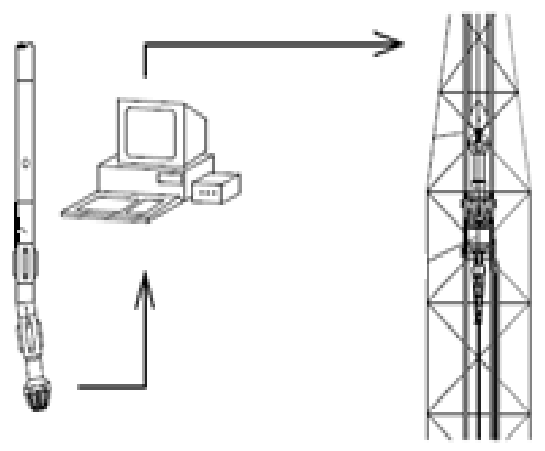

Figure. 1 Drilling installation with automated guiding structure designed for guided drilling with TOP DRIVE

The continuous evolution of the top drive systems (the hydraulic head is mounted on a mobile platform running on the guiding structure) has led to a variety of technical solutions based on economic analysis programs. SASKOIL (Canada), shows that using such a system attached to a conventional drilling rig the total construction cost of a well is reduced by $10 \%$ by reducing auxiliary time and increasing operating safety for working at steady maneuvering speeds the well regardless of climatic conditions.

In conclusion, the top drive system will be used in directional drilling and super-drilling, and in terms of the cost of one meter drilled using this system, it will decrease.

The advantages of using the top drive system are already established, the only observation being that the system was taken over in a very short time by world-renowned oil companies specializing in the construction of oil equipment, and the opening of design objectives also addresses issues related to increasing system reliability and finding design methods to ensure technical risk.

The American company NATIONAL OILWELL in Huston delivered to ARABIAN GULF EMIRATE company in Abu Dhabi several types of plant including a plant with a guiding structure capable of digging up to a maximum depth of $8000 \mathrm{~m}$; here is an example of an installation that, according to the above-mentioned requirements, was designed to drill deep-sea wells in desert conditions.

TRITON FRANCE, thanks to the high degree of automation and mechanization of the configuration of the unconventional maneuvering system with guiding structure, succeeds in reducing by $50 \div 75 \%$ the cost of the slimholes drilling operation in relation to the drilling operation with a plant conventional.

TRITON FRANCE belongs to the French company FORASOL and has the guiding structure resulting from the modification of the 18-meter-wide $\mathrm{W}-\mathrm{N}$ Apache mast with a maximum hook load (mobile platform) of $140 \mathrm{kN}$. The maximum drilling depth recommended $\mathrm{HM}=2200 \mathrm{~m}$

or a well with a diameter of DS $=127 \mathrm{~mm}$. Max power at the PM hydraulic motor head $=260 \mathrm{~kW}$ required to rotate the drill string.

In 1987, AMOCO PRODUCTION COMPANY (USA) launched a research program designed to design and build a drilling rig with unconventional maneuvering and guidance structure. The project was called the "Stratigraphic High Speed
Advanced Drilling System" (SHADS), according to the intended destination of the new drilling rig, namely geological research and prospecting. In May 1991, the partnership between AMOCO and NABORS INDUSTRIES INC, which is affiliated to the SHADS project, is established.

The cooperation of the two companies resulted in the construction of the NABORS RIG No.170 drilling rig, completed in early 1993.

The NABORS No.170 Drilling System has the following features:

- mast: DRECO with a height of $26 \mathrm{~m}$;

- maximum lifting force at the hydraulic motor head located on the mobile platform of the installation: $\mathrm{FCM}=956$ $\mathrm{kN}$;

- substructure: DRECO SLINGSHOT 4.6 m high;

- Hydraulic motor head: DRECO HYDRAULIC with maximum working power $\mathrm{PM}=260 \mathrm{~kW}$;

- two drilling pumps with a maximum power of $123 \mathrm{~kW}$ each, for the hydrostatic drive system of the unconventional maneuvering system;

- the maximum stroke the hydraulic motor head can make is $8 \mathrm{~m}$;

- the drilling rig is so designed that it can be transported by helicopter in containers not exceeding in excess of the maximum value $\mathrm{GM}=27 \mathrm{kN}$;

- the plant is equipped with an Equivalent Circulating Density (ECD);

- AMOCO has developed specifically for the No170 installation an expert system for controlling and tracking the technological process for the "Expert Well Control System" (XWC).

Initial evidence was conducted in Wyoming (USA) where a well was excavated at $3816 \mathrm{~m}$. The preliminary conclusions were very good, confirming the expectations of the specialists.

The total investment cost for digging the well is $41 \%$ lower than the conventional drilling rig. This cost reduction is due both to the reduction of the auxiliary time and to the increased efficiency and safety of the drilling technology. It can be said that the solution of the hydrostatic drive system with a guiding structure, according to the current technical level, is necessary as an optimal solution for the modernization of the drilling installations.

In Canada, PANCANADIAN PETROLEUM Ltd. of Calgary designed and built a series of drilling installations with unconventional maneuvering system and guiding structure for sloping drilling.

One of the PanCanadian plants can drill 60 degree tilt angle of the oval vertical at $6086 \mathrm{~m}$ deep.

The drilling installation presents as a peculiarity the existence of the guiding structure on which the mobile hydraulic head assembly runs. In the case of the inclined drilling, the existence of the guiding structure is important to ensure correct guidance of the hydraulic motor head in the specific forces taking over due to the inclination of the oval. Such installations have been located on landfills and offshore drilling platforms, and their exploitation has led to important successes materialized in increasing the efficiency of the drilling process, reducing costs by lowering auxiliary times and increasing operational safety. 
Application possibilities of inclined or guided drilling can also be found on land structures with access difficulties, areas with strong landslides, as follows:

- on Tazlau structure - wells with a depth of $1100 \mathrm{~m}$;

- on the Nineasa-South structure - wells with a depth of $750 \div 800 \mathrm{~m}$;

Based on these requirements, the tilting properties of the tower result, and in some cases the rising angle of the inclination angle when the maximum possible inclination of the tower $\left(45^{\circ}\right)$ would not ensure the required horizontal displacement.

A diverted well, conventionally drilled, typically starts with a vertical trace. Depth or deep-sea motors with special construction are then used to deflect the well with the appropriate angle to reach its target.

Conventional drilling method (by deviation) increases the measured length of the well, because it does not follow the shortest distance between two points: a straight line. The additional length plus the need for specialized equipment lead to higher drilling costs. By comparison, the inclined drilling succeeds the shortest drilling distance by allowing the well to be drilled at an angle (usually up to $45^{\circ}$ ) oriented directly towards the target (Figure 1.3, b).
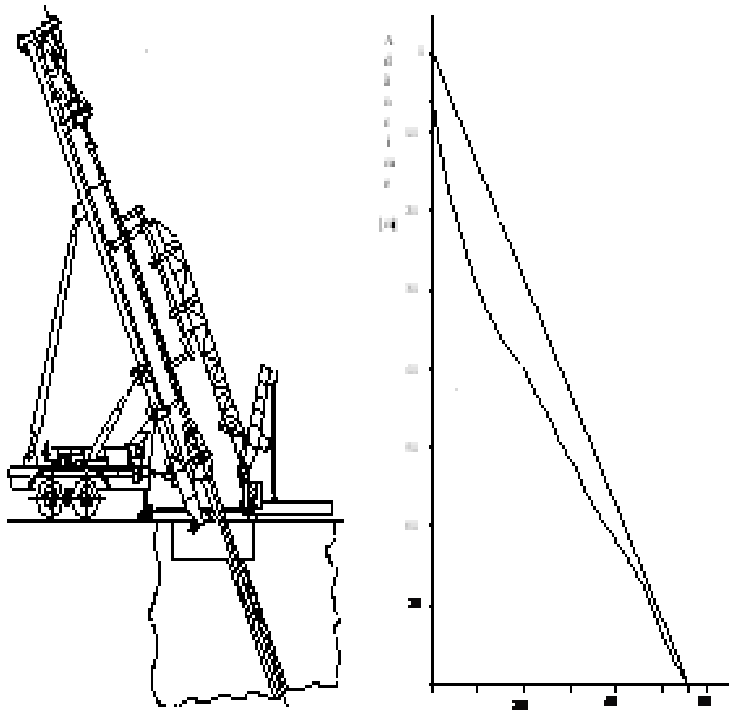

Figure 2. Comparative analysis of the horizontal movement of the drill between the guided and the inclined drilling:

a) the schematic diagram of an inclined drilling installation

b) Comparison diagrams of trajectories length.

With a suitable drilling rig, the well can be drilled directly to the target (fig. 2).

For the inclined drilling in the literature, the name of the inclined spindle drilling is also used.

The use of sloping drilling technology will require an increased number of drilling installations capable of operating either vertically or inclined with a guiding structure.

The technology of drilling of drilled wells has been applied heavily in heavy-duty, low-pitched areas.

Below are three examples of shore-side drilling programs: - heavy oil drilling in Alberta;
- gas drilling in Alberta;

- Drilling for subtracting a watercourse with a gas pipeline in British Columbia.

A slanted hole drilling project has been developed to drill 23 wells from a battery near Walf Lake in the northern sector of Alberte. This area of Canada has one of the world's richest deposits of crude oil.

The program required 10 sloping wells, of which 6 wells were drilled at $30^{\circ}$; two at $29^{\circ}$; one at $27^{\circ}$ and one at $26^{\circ}$. The remaining 13 wells were started vertically and continued with conventional drilling wells. A second drilling project of an inclined well involved a shallow gas well drilling for Grand Prix Natural Gas Ltd near Brook in South Alberta. In addition to conventional drilling practices in the oil field, sloping drilling technology has been used to drill a river undertraversion. For the first two examples of projects, the Sierra operator used Failing FS-5000 systems with a drilling capacity of up to $1700 \mathrm{~m}$. These installations are mounted on trailers and equipped with unconventional maneuvering systems and guiding structures.

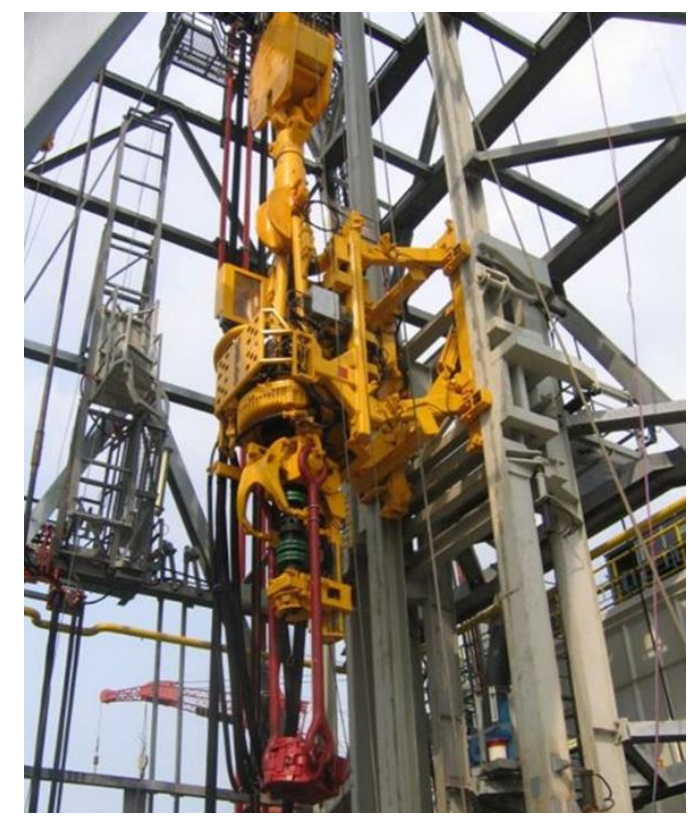

Figure 3. TOP DRIVE system

\section{THE MAIN TECHNOLOGICAL PROBLEM. IDENTIFICATION, EVALUATION AND SOLUTIONS}

It is known that the drilling time is the main component that relates to the drilling costs and it is determinant that the auxiliary time is minimal, if possible even zero, which means that the maneuvering speed has the value permanently maximum possible dictated by the technological process served and the strength of the structure's resistance structure.

Another cause may be ball bearings; a verification according to the technical requirements in accordance with API standards is required to prevent uncontrolled shutdown.

Also sharpening of the rails edges from the guide system can stop the system as it will trap metal particles between the patina and the rail.

\footnotetext{
${ }^{1}$ https://www.nov.com/Segments/Rig_Systems/Offshore/Top_Drive_Systems/ Fixed_Electric_Top_Drives/TDS-8_Top_Drive.aspx
} 
Changing the center of gravity of the counterbalance system to the drive system axis.

Turning the pane handling system when tilted will result in a failure of the pendulum clamping system, with the only replacement solution because the refurbishment can only be done in special workshops.

The TOP DRIVE system assemblies are designed to assemble the components that make up the entire system, to ensure a proper sealing of the system design parameters and last but not least to facilitate access to any system sub-assembly by removing them so that they can intervene in case of damage or maintenance.

Assembly assemblies for assembling TOP DRIVE components are manufactured in accordance with ASME and ASTM standards. Due to the forces acting on the TOP DRIVE system during drilling and environmental conditions that influence the strength of these fasteners, they fail to create an uncontrolled stop.

Fatigue breakage occurs progressively under the action of variable stresses, even if the stretching or compression tension is less than the material's elastic limit. Local stresses may be higher than the material flow limit due to stress concentration around inclusions or microtips. In this case plastic deformations occur at microstructural level. Fatigue breakdown is conditioned by three factors:

$\square$ stretching tension;

plastic deformations;

cyclical or variable requests.

Plastic deformations occur in the crystals through packets of atoms. At alternating stresses, if the slides are limited and the materials are sufficiently localized, the sliding can be stopped, contrary to the slopes in the most demanding areas progressing, turns into one or more visible eye-cracking, which increases, decreases continuously section until it becomes insufficient to withstand the applied forces, causing the assembly to break in the case presented, dictated by the technological process served and the structural strength of the structure

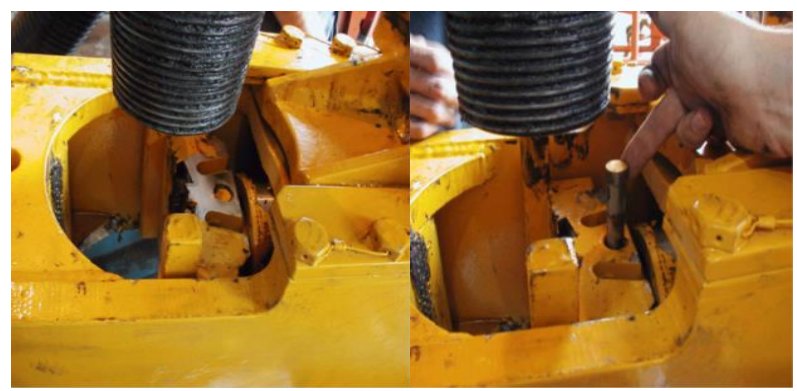

Figure 4. Dropping of a bolt from the rotary head TOP DRIVE

\section{III.1 EVALUATION OF THE PROBLEM}

The components of the machine in operation were tracked until damage occurred. This allowed to obtain the values of the time of good functioning presented in Table 1. It is aimed at the statistical processing of these data.

The experimental values, listed in Table 1, are presented in ascending order (statistical string), so that the two extreme values can be identified

$\mathrm{xmin}=1.096$ ore $; \operatorname{xmax}=2.873$ ore

The amplitude of string $\mathrm{R}$ results immediately,

$\mathrm{R}=\mathrm{x} \_\max -\mathrm{x} \_\min =2.873-1.096=1.777$ ore
For calculating statistical sizes, it is often useful to group data by classes (ranges). The number of classes $\mathrm{k}$ is recommended to be between 13 and 20. If the number of data is less than 250, it is sufficient to divide into 10 classes.

Next, it is intended to group the data into k intervals or classes.

Taking into account the recommendations for determining the number of classes, an average value was adopted, ie $\mathrm{k}=11$ classes

Table 1. Good operation for TOP DRIVE

\begin{tabular}{|l|l|l|l|l|l|l|l|}
\hline $\mathbf{i}$ & $\mathbf{x}_{\mathbf{i}}$ (hours) & $\mathbf{i}$ & $\mathbf{x}_{\mathbf{i}}$ (hours) & $\mathbf{i}$ & $\mathbf{x}_{\mathbf{i}}$ (hours) & $\mathbf{i}$ & $\mathbf{x}_{\mathbf{i}}$ (hours) \\
\hline 1 & 1,096 & 12 & 1,736 & 23 & 2,047 & 34 & 2,305 \\
\hline 2 & 1,196 & 13 & 1,801 & 24 & 2,084 & 35 & 2,368 \\
\hline 3 & 1,268 & 14 & 1,827 & 25 & 2,118 & 36 & 2,402 \\
\hline 4 & 1,296 & 15 & 1,833 & 26 & 2,133 & 37 & 2,418 \\
\hline 5 & 1,474 & 16 & 1,836 & 27 & 2,139 & 38 & 2,454 \\
\hline 6 & 1,486 & 17 & 1,854 & 28 & 2,148 & 39 & 2,534 \\
\hline 7 & 1,563 & 18 & 1,890 & 29 & 2,194 & 40 & 2,607 \\
\hline 8 & 1,566 & 19 & 1,986 & 30 & 2,214 & 41 & 2,676 \\
\hline 9 & 1,540 & 20 & 2,005 & 31 & 2,214 & 42 & 2,704 \\
\hline 10 & 1,565 & 21 & 2,010 & 32 & 2,227 & 43 & 2,796 \\
\hline 11 & 1,572 & 22 & 2,041 & 33 & 2,244 & 44 & 2,873 \\
\hline
\end{tabular}

For each class are established:

The common amplitude of classes (a),

$$
\mathrm{a} \cong \mathrm{R} / \mathrm{k}=\left(\left(\mathrm{x} \_ \text {max }-\mathrm{x} \_\min \right)\right) / \mathrm{k}=1.777 / 11 \cong 160
$$

The center values $\mathrm{xj}$ of the classes, starting from the choice of the central value of the first class at a distance less than half the class amplitude from xmin, followed by the relation $\llbracket x \rrbracket_{-}(j+1) \llbracket=x j_{-} j+a$

$$
x_{-} 1=1132 ; x_{\_} j=1 ; x_{-} j=160 ; j=1,2, \ldots, 10 ;[5]
$$

Limit values of classes are calculated, respectively, with the expressions

$$
x_{-} j-a / 2, x_{-} j+a / 2, j=1,2 \ldots 10[6]
$$
Table 2.

All core values xj and class limit values are shown in

The frequency histogram is a representation equivalent to the polygon of the frequencies, with the difference that rectangles are represented, with the base equal to the amplitude of the classes (a) and the height proportional to the frequency of the absolute or relative classes (Figure 5). 
Table 2. Frequency table

\begin{tabular}{|c|c|c|c|c|c|c|c|}
\hline \multirow{2}{*}{$\begin{array}{l}\text { Nr. } \\
\text { class } \\
\mathrm{j}\end{array}$} & \multirow{2}{*}{$\begin{array}{c}\text { Value } \\
\text { plant } \\
x j \\
\text { [ore] }\end{array}$} & \multirow{2}{*}{$\begin{array}{l}\text { Limit } \\
\text { class } \\
\text { xj,inf } \\
\text { [ore] }\end{array}$} & \multirow{2}{*}{$\begin{array}{c}\text { Limitt } \\
\text { class } \\
\text { xj,sup } \\
\text { [ore] }\end{array}$} & \multicolumn{2}{|c|}{ frequency class } & \multicolumn{2}{|c|}{$\begin{array}{l}\text { cumulative } \\
\text { frequency, Fj }\end{array}$} \\
\hline & & & & $\begin{array}{l}\text { Absolut } \\
\text { nj[buc.] }\end{array}$ & $\begin{array}{c}\text { Relative } \\
\text { fj [-] }\end{array}$ & $\begin{array}{l}\text { Absolute } \\
\text { [buc.] }\end{array}$ & $\begin{array}{c}\text { Relativ } \\
{[-]}\end{array}$ \\
\hline 1 & 1,146 & 1,066 & 1,226 & 2 & 0.045 & 2 & 0.045 \\
\hline 2 & 1,282 & 1,202 & 1,362 & 2 & 0.045 & 4 & 0.091 \\
\hline 3 & 1,508 & 1,428 & 1,588 & 3 & 0.068 & 7 & 0.159 \\
\hline 4 & 1,561 & 1,481 & 1,641 & 4 & 0.091 & 11 & 0.250 \\
\hline 5 & 1,825 & 1,745 & 1,905 & 7 & 0.159 & 18 & 0.409 \\
\hline 6 & 2,063 & 1,983 & 2,143 & 9 & 0.205 & 27 & 0.614 \\
\hline 7 & 2,207 & 2,127 & 2,287 & 6 & 0.136 & 33 & 0.750 \\
\hline 8 & 2,389 & 2,309 & 2,469 & 5 & 0.114 & 38 & 0.864 \\
\hline 9 & 2,606 & 2,526 & 2,686 & 3 & 0.068 & 41 & 0.932 \\
\hline 10 & 2,750 & 2,670 & 2,830 & 2 & 0.045 & 43 & 0.977 \\
\hline 11 & 2,873 & 2,793 & 2,953 & 1 & 0.023 & 44 & 1.000 \\
\hline 2 & - & - & - & 44 & 1.000 & - & - \\
\hline
\end{tabular}

Of the graphical representations, based on the data in the frequency table, figure 5 shows the frequency histogram. It shows that the empirical distribution is a single maximum distribution and that it has a reduced asymmetry. In this regard, we will analyze each subsystem of the TOP DRIVE system to determine their failure rates in order to establish a maintenance plan in order to avoid uncontrolled stoppages during the operation.

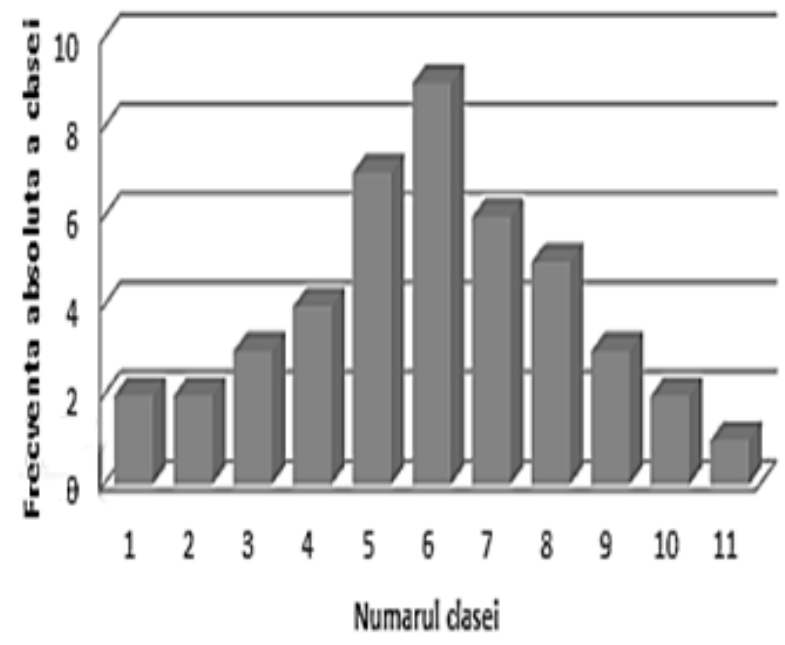

Figure 5. Frequency Histogram

Se vor analiza cele 4 componente ale sistemului TOP DRIVE following the observance of the normal distribution law (Gauss-Laplace). In this regard, we determine whether the collected data is correct or whether other factors have affected the system's TOP DRIVE system failure.
Once the accuracy of the data and the calculations has been established, the maintenance plan and, implicitly, the implementation plan will be drawn up.

\section{TOP DRIVE UTILITY MENTENANCE. MENTENANCE STRATEGY}

An analysis of maintenance is best done by taking into account two forms of management (management): one short-term (usually annual), which we call maintenance policy, and another, long-term, covering the entire period planned operation of the machine, which we will call a maintenance strategy. In the following, we will stop, in particular, on the maintenance policy.

Maintenance activities can be grouped on multiple components. Imperfections and unavoidable failures of production equipment require, above all, technical intervention, which is why it is a primary component.

Technical maintenance interventions are usually composed of numerous and varied works, in nature, in their form and in time. The correct and timely execution of these works, in installations of some importance, raises the issue of organization, so organization is the second essential component of maintenance.

Maintenance actions, whatever their intrinsic quality, do not fully achieve their purpose unless they are strictly organized, all the more so as they are extremely varied.

Specialized publications propose organizational models that, although very elaborate, should be considered as a reserve, given the very difficult ways to apply it.

The most important general principles of the organization are as follows:

-degining the organizational chart;

-administration of operations;

-organization of workshops;

-planning studies and works

For serviceability in the maintenance plan, the availability of spare parts in stock is very important at the start of maintenance operations on the TOP DRIVE system.

Usually delivery time for spare parts is an average of 30 days.

In view of the weekly verification required by the manufacturer through the Product Report issued by CANRIG DRILLING TECHNOLOGY LTD [2] and based on calculations setting fixed maintenance, a minimum stock is required to cover the period between two supplies and namely 30 days.

Following the PDCA cycle, we will need to plan the improvement project, and as a first step we need to identify the people concerned.

The potential list of measurements should be categorized to ensure that they provide a balanced picture of the project. For example, you do not want to end up with a single set of financial measurements, even if it is the easiest to achieve. In general, we are looking for measurements that provide information in areas such as:

- Cost

- Effort

- Duration

- Productivity

- Quality of materials

- Performance of the project team

It can be used as a guiding tool throughout the improvement project or for the development of specific projects when areas that need to be improved are identified as follows:

Plan - Plan

Set goals

Establish the necessary methods

Do - Execute

Educate and prepare

runs

Check - Check 
Check out the results of the work

Act - Act

Establish the necessary measures according to the results CONCLUSIONS

The evolution of drilling installations over the last few years is spectacular and includes the entire range of drilling installations. This evolution is launched in two main directions.

A first direction in the evolution of the modernization of drilling installations is the introduction of economical and reliable drive systems, of which, according to the current technological accessibility level, the electric drive systems are emphasized.

The second direction is manifested by the solutions of increasing the degree of mechanization and automation of the operations specific to the work systems, especially the reduction of the total duration of the total maneuver time, which means the reduction of the auxiliary times to a minimum (even at zero).

Corresponding to the two main requirements outlined above, it is noted that rigorous maintenance is also required on the auxiliary components of the TOP DRIVE system, which can lead to delays.

It is noted that modifications have been made to the structure resistance of the installation by ensuring the possibility of guiding the mobile equipment in order to meet both of the above mentioned requirements, which are most often major changes, and the structure can be named according to the function that fulfills the guiding structure. But the subassemblies are the same. It is obvious that in an improved system will yield the weakest mark, but if this is known and has developed a coherent maintenance plan, then we can say that the risk of accidental intrusions is very low, and if there are interruptions caused by organs assembly will be solved without affecting drilling time.

There is a desideratum; through the analysis of the technical systems it is intended that the system should operate at optimal parameters, without interruption and without causing injuries. This is, in fact, the essential condition of quality work.

During operation, the TOP DRIVE system suffers from wear and tear, which can affect not only their proper functioning but can have serious consequences, such as damage to the system or even personal injury to the production process.

The analysis made was able to determine the probability of failure, the risk of a machine slipping during operation and the maintenance plan was developed to ensure operation in normal parameters, taking into account the following aspects:

Avoiding overloads;

- observing the working parameters;

- observance of the mounting conditions, as well as ensuring the optimum environment conditions;

- observing the working interval, but also the breaks specific to each machine or plant;

- servicing the machine and the installation by qualified personnel;

- Cleaning and proper maintenance;

- lubrication of moving parts;

- Continuous monitoring of the operation, as well as checking the operating parameters;
- observing the maintenance schedule;

- troubleshooting as soon as they occur;

- Making repairs and maintenance by qualified personnel;

- periodically checking the condition and functionality of the accessories used.

\section{REFERENCES}

[1] Din analele Universităti "Constantin Brâncuși" Târgu Jiu Seria Inginerie, Nr. 3/2012

[2] Canrig Drilling Technology LTD - CANRIG TD PRODUCT BULLETIN MANUAL

[3] Marian Neacsu - curs Ingineria si Managementul Mentenantei Universitatea de Petrol si Gaze -Ploiesti - 1998.

[4] Eni Corporate University- DRILLING \& COMPLETION ENGINEER - 11/10/2006 FEDERAL ENERGY MANAGEMENT PROGRAM-

[5] Operations \& Maintenance - Best Practices - A Guide to Achieving Operational Efficiency - 2010

ASM Metals Handbook, Vol.1\&2, 10th Edition.

Ordinul MMPS nr. 225 din 27 iulie 1995

Normele Specifice de Securitate a Muncii 